\title{
Esophageal Stent Insertion for Postesophagectomy Anastomosis Site Leakage
}

\author{
Sang Yoon Kim · Chang Hyun Kang · In Kyu Park · Young Tae Kim \\ Department of Thoracic and Cardiovascular Surgery, Seoul National University Hospital, Seoul, Korea
}

In Ivor Lewis operation, anastomosis site leakage is a critical complication. Interventional approach utilizing covered metal stent has been introduced for the management of this complication. This patient was diagnosed as esophageal cancer and underwent robot-assisted Ivor Lewis operation. Due to symptoms suggesting anastomosis site leakage, video-assisted thoracoscopic surgery exploration was performed without identification of gross leakage site. On esophagogastroduodenoscopy, anastomosis site leakage was detected and esophageal stent was placed. Four weeks later, the stent was removed, and the patient could intake all his diet orally without discomfort. Esophageal stent insertion can be an option to manage postesophagectomy leakage problem.

Keywords. Stents; Anastomotic Leak; Esophagectomy; Postoperative Complications; Esophageal Neoplasms

\section{INTRODUCTION}

Esophagectomy and esophagogastrostomy is a standard procedure in surgical treatment of esophageal cancer. However, leakage of anastomosis site results in critical morbidity and mortality. In management of this leakage problem, endoscopic intervention can take a role during conservative approach, and can be an alternative of surgical approach. Esophageal stents are placed to treat leakage problem with satisfying result in experienced centers [1]. However, there has not been a documented case in Korea. We present a case in which anastomosis leakage was successfully controlled by stent insertion.

\section{CASE REPORT}

The patient was 65-year-old gentleman who had history of old medullary infarction without sequele. With social history of heavy drinking and smoking of 20 pack-year, he visited out-pa-

\footnotetext{
- Received May 5, 2015

Revised June 16, 2015

Accepted July 8, 2015

- Corresponding author: Chang Hyun Kang

Department of Thoracic and Cardiovascular Surgery, Seoul National

University Hospital, 101 Daehak-ro, Jongno-gu, Seoul 03080, Korea

Tel: +82-2-2072-3010, Fax: +82-2-764-3664

E-mail: chkang@snu.ac.kr
}

tient clinic due to dysphagia and chest pain. On esophagogastroduodenoscopy, ulcerofungating mass on esophageal mucosa at 30-33 cm below upper incisor was detected and biopsied. The pathologic report of the mass was invasive squamous cell carcinoma. Muscle layer invasion was suspicious in endoscopic ultrasound finding. There was no evidence of systemic or regional lymph node metastasis.

Robot-assisted Ivor Lewis operation was performed. Both abdominal and thoracic procedures were performed by robot-assisted technique. Gastric conduit was made intracorporeally and intra-abdominal lymph nodes were dissected to the level of celiac axis. Pyloromyotomy was performed and jejunostomy was made at proximal jejunum. In thoracic phase thoracoscopic adhesiolysis was performed due to severe pleural adhesion. After esophagectomy, mediastinal lymph node dissection up to both recurrent laryngeal lymph nodes was performed. With 25-mmsized endoscopic end-to-end anastomosis stapler, intrathoracic esophagogastrostomy was carried out above azygos vein. Reinforcement sutures with 4-0 black silk were placed on the anastomosis site.

On the third postoperative day, high fever up to $38.4^{\circ} \mathrm{C}$ occurred and blood exam demonstrated leukocytosis and elevated C-reactive protein. At the following day, color of chest tube drainage changed to dark greenish and total bilirubin concentration from chest tube drain was $6.5 \mathrm{mg} / \mathrm{dL}$. Chest computed tomography revealed loculated pleural effusion on right thoracic

Copyright () 2016 by Korean Society of Otorhinolaryngology-Head and Neck Surgery.

This is an open-access article distributed under the terms of the Creative Commons Attribution Non-Commercial License (http://creativecommons.org/licenses/by-nc/4.0)

which permits unrestricted non-commercial use, distribution, and reproduction in any medium, provided the original work is properly cited. 

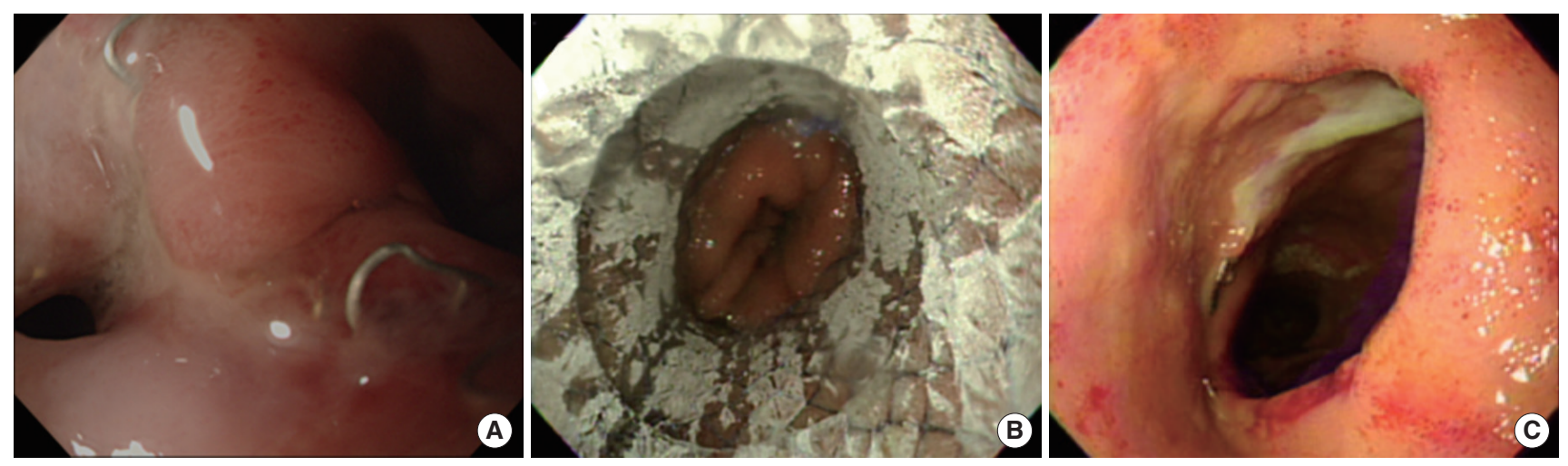

Fig. 1. (A) Esophageal leakage tube on esophagogastroduodenoscopy before stent insertion. (B) Deployed esophageal stent. (C) Healed esophageal leakage site after removal of esophageal stent.

cavity. For drainage of effusion and identification of leakage point, thoracoscopic exploration was performed. However, gross leakage point could not be identified after draining loculated contaminated fluid. Fever was controlled and general condition of the patient was improved rapidly. However persistent leukocytosis was not normalized 2 weeks after thoracoscopic exploration. Esophagoscopy was performed 17 days after thoracoscopic exploration to detect any residual leakage point. Esophagoscopy demonstrated multiple ulcer and a leakage hole on anastomosis site (Fig. 1A). Covered metal stent $(18 \mathrm{~mm} \times 60 \mathrm{~mm}$; Bonastent Esophageal, EndoChoice Inc., Alpharetta, GA, USA) was placed in leakage site (Fig. 1B). Two weeks after stent insertion, esophagoscopy was performed to check proper position of stent, 2 weeks thereafter, the stent was removed endocopically (Figs. $1 \mathrm{C}, 2)$. No evidence of leakage was found in esophagogram. One week after stent removal, patient was discharged with full nutritional intake via oral route exclusively. The patient is now on regular outpatient follow-up without evidence of anastomosis site stricture for 10 months after esophagectomy.

\section{DISCUSSION}

The incidence of anastomotic leakage after esophagectomy is estimated $11 \%$ by a recent review of The Society of Thoracic Surgeons general thoracic surgery database. And the influence of this significant complication pose the patient in high mortality

\section{H}

- Esophageal stent is another treatment option for post-esophagectomy anastomotic leakage.

- Esophageal stent can preserve the benefit of minimally invasive primary treatment.

- Even in case of failure of surgical repair, esophageal stent insertion is applicable.

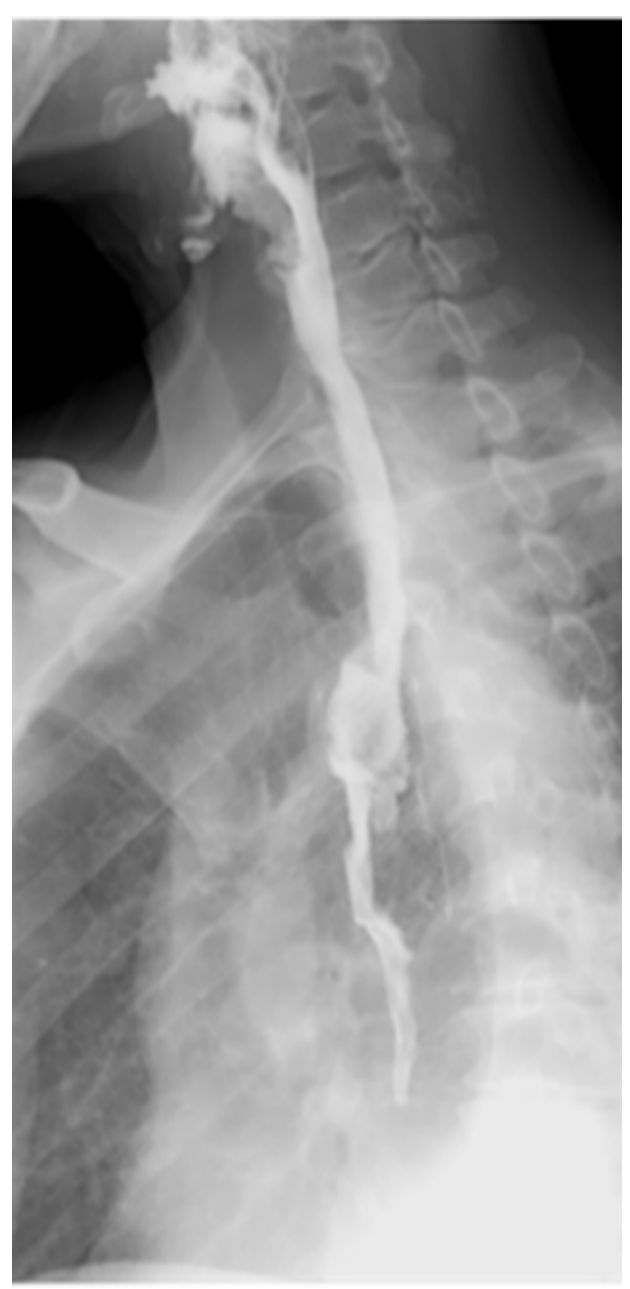

Fig. 2. Esophagogram before retrieval of esophageal stent. There was no visible leakage in the esophagogram.

of $35.7 \%$ contrast to $4.2 \%$ of those without leakage [2]. As conventional treatment, surgical repair of the anastomosis site leakage demonstrated $71.4 \%-100 \%$ success rate.

In 1996, Segalin et al. [3] reported 2 successful cases of en- 
doscopic esophageal stent placement for the treatment of postoperative esophageal leakage. Prior to the report, endoluminal prosthesis had been adopted to treat malignant fistula caused by esophageal cancer, but not in postoperative setting. Reports on esophageal stent for the treatment of postoperative leakage arose around 2005. The success rates of esophageal stent range from $59.1 \%$ to $94.1 \%$. Of those successful cases, included were an anastomotic leak encompassing approximately $50 \%$ of the original anastomotic circumference and a leakage whose size was larger than $5 \mathrm{~cm}$. Although stent migration was the most common complication, endoscopic removal and reinsertion of stent was feasible. Other than stent migration, stricture after stent removal and tracheoesophageal fistula were reported as related complication, and one patient expired due to fatal gastro-aortic fistula [4-6]. In 2011, Freeman et al. [2] reported $94.1 \%$ success rate in acute intrathoracic anastomotic leakage after esophagectomy. When it comes to the excellent occlusion rate of theirs, exclucion criteria should be remarked such as leakage from gastric conduit itself remote from the anastomosis, complete dehiscence of the anastomosis and conduit other than stomach.

While the number of robot-assisted esophagectomy has been increasing, anastomotic leakage is still one of the common complications. As in our case, stent insertion can be helpful in the aspect of noninvasiveness, which was minimized by robot-assisted procedure.

There has not been yet any prospective clinical study, which compared the outcome of esophageal stent to that of conservative/surgical treatment. Only a retrospective study comparing esophageal stent with conventional treatment was published and revealed esophageal-stent-favoring outcome with better leakage control, shorter length of hospital stay [7]. Esophageal stent might not be successful in some cases if the defect is large, or if the viability of tissue around defect is low, which is the common situation of patients with neoadjuvant chemoradiation treatment for locally advanced esophageal cancer. However in the series which Freeman et al. [2] reported, 15 patients with neoadjuvant chemoradiation were included in successful cases. It implicates that further application and spread of indication are forecasted. Not only substituted for the surgical repair, esopha- geal stents can also take a supplementary role to the surgical repair, functioning as buttress and barrier to gastrointestinal contents [8]. Still there are a lot of questions to be answered, such as the outcomes in patient with trachea-esophageal fistula or with leakage at the site of conduit necrosis, etc. Answering the remained questions, further utilizing of the device is being anticipated.

\section{CONFLICT OF INTEREST}

No potential conflict of interest relevant to this article was reported.

\section{REFERENCES}

1. Freeman RK, Ascioti AJ. Esophageal stent placement for the treatment of perforation, fistula, or anastomotic leak. Semin Thorac Cardiovasc Surg. 2011 Summer;23(2):154-8.

2. Freeman RK, Vyverberg A, Ascioti AJ. Esophageal stent placement for the treatment of acute intrathoracic anastomotic leak after esophagectomy. Ann Thorac Surg. 2011 Jul;92(1):204-8.

3. Segalin A, Bonavina L, Lazzerini M, De Ruberto F, Faranda C, Peracchia A. Endoscopic management of inveterate esophageal perforations and leaks. Surg Endosc. 1996 Sep;10(9):928-32.

4. Al-issa MA, PetersenTI,Taha AY, Shehatha JS.The role of esophageal stent placement in the management of postesophagectomy anastomotic leak. Saudi J Gastroenterol. 2014 Jan-Feb;20(1):39-42.

5. Langer FB, Wenzl E, Prager G, Salat A, Miholic J, MangT, et al. Management of postoperative esophageal leaks with the Polyflex self-expanding covered plastic stent.Ann Thorac Surg. 2005 Feb;79(2):398403.

6. D'Cunha J, Rueth NM, Groth SS, Maddaus MA, Andrade RS. Esophageal stents for anastomotic leaks and perforations. JThorac Cardiovasc Surg. 2011 Jul;142(1):39-46.e1.

7. Nguyen NT, Rudersdorf PD, Smith BR, Reavis K, Nguyen XM, Stamos MJ. Management of gastrointestinal leaks after minimally invasive esophagectomy: conventional treatments vs. endoscopic stenting. J Gastrointest Surg. 2011 Nov;15(11):1952-60.

8. Blackmon SH, Santora R, Schwarz P, Barroso A, Dunkin BJ. Utility of removable esophageal covered self-expanding metal stents for leak and fistula management. Ann Thorac Surg. 2010 Mar;89(3): 931-6. 